\title{
Glycaemic index of selected staples commonly eaten in the Caribbean and the effects of boiling $v$. crushing
}

\author{
D. Dan Ramdath ${ }^{1}$, Renée L. C. Isaacs ${ }^{2}$, Surujpal Teelucksingh ${ }^{3}$ and Thomas M. S. Wolever ${ }^{2 \star}$ \\ ${ }^{1}$ Department of Preclinical Sciences, Faculty of Medical Sciences, The University of the West Indies, St Augustine, \\ Trinidad and Tobago \\ ${ }^{2}$ Department of Nutritional Sciences, University of Toronto, Faculty of Medicine, Toronto, Ontario, M5A 3E2, \\ Canada \\ ${ }^{3}$ Clinical Medical Sciences, Faculty of Medical Sciences, The University of the West Indies, St Augustine, \\ Trinidad and Tobago
}

(Received 22 July 2003 - Revised 22 January 2004 - Accepted 11 February 2004)

\begin{abstract}
Integrating information about the glycaemic index (GI) of foods into the Caribbean diet is limited by the lack of data. Therefore, we determined the GI of eight staple foods eaten in the Caribbean and the effect on GI of crushing selected tubers. Groups of eight to ten healthy volunteers participated in three studies at two sites. GI was determined using a standard method with white bread and adjusted relative to glucose. The mean area under the glucose response curve elicited by white bread was similar for the different groups of subjects. In study 1, the GI of cassava (Manihot esculenta; 94 (SEM 11)) was significantly higher than those of breadfruit (Artocarpus altilis; 60 (SEM 9)), cooking 'green' banana (Musa spp.; 65 (SEM 11)) and sadha roti (65 (SEM 9)) $(P=0.018)$. There was no significant difference in the GI of the foods in study 2: dasheen (Colocasia esculenta var. esculenta; 77 (SEM 10)), eddoes (Colocasia esculenta var. antiquorum; 61 (SEM 10)), Irish potato (Solanum tuberosum; 71 (SEM 8)), tannia (Xanthosoma sagittifolium; 60 (SEM 5)) and white yam (Dioscorea alata; 62 (SEM 6)), and, in study 3, crushing did not significantly affect the GI of dasheen, tannia or Irish potato. However, when the results from studies 2 and 3 were pooled, the GI of dasheen (76 (SEM 7)) was significantly greater than that of tannia (55 (SEM 5); $P=0.015$ ) with potato being intermediate (69 (SEM 6)). We conclude that dasheen and cassava are high-GI foods, whereas the other tubers studied and sadha roti are intermediate-GI foods. Given the regular usage of cassava and dasheen in Caribbean diets we speculate that these diets would tend to be high GI, although this could be reduced by foods such as sadha roti and white yam. The range of GI between the staples is sufficiently large that health benefits may be accrued by replacing high-GI staples with intermediate-GI staples in the Caribbean diet.
\end{abstract}

Glycaemic index: Caribbean: Diabetes: Glucose

The glycaemic index (GI) is a classification of the glucose-rising potential of carbohydrate foods relative to glucose (Wolever et al. 1991). Recent studies have shown that the regular consumption of diets containing high-GI foods is associated with an increased risk for type 2 diabetes mellitus (Salmeron et al. 1997a,b) and CHD (Ford \& Liu, 2001; Liu \& Manson, 2001). In contrast, the inclusion of low-GI foods in the diet, with no change in the total amount of carbohydrate consumed, may improve blood glucose control (Brand et al. 1992), reduce serum triacylglycerols (Jenkins et al. 1987), prolong endurance during physical activity (Thomas et al. 1991) and improve insulin sensitivity (Byrnes et al. 1995; Frost et al. 1998). The GI may therefore provide the rationale for choosing carbohydrate foods for meal plans created for individuals with diabetes (Food and Agriculture Organization of the United Nations, 1998).
In addition, low-GI diets could be incorporated into health promotion messages for the reduction of risk for type 2 diabetes and CHD.

In the Caribbean, type 2 diabetes and CHD are the leading causes of morbidity and mortality. In Trinidad and Tobago the prevalence of diabetes is the highest in the Caribbean and approximately six times higher than that in North America (Gulliford et al. 1995; Gulliford, 1996). The annual financial cost of admission for diabetes has been conservatively estimated at TT\$ 10.66 million (UK $£ 1.24$ million) (Gulliford et al. 1995). Predominantly a migrant population from Africa and South Asia, the Caribbean has in turn seeded a secondary wave of migrants to many metropolitan areas of North America and Europe. In developed countries, migrant Caribbean populations continue to have a high incidence of diabetes wherever they have settled (Cruickshank et al. 1991; Cooper et al. 1997). 
Caribbean guidelines for the dietary management of diabetes and CHD risk reduction are based on six food groups, and the main dietary staples are 'ground provisions' and 'grains and cereals' (Caribbean Food and Nutrition Institute, 1994). Foods in the former group include tubers, breadfruit (Artocarpus altilis) and cooking 'green' banana (Musa spp.), which is a different variety from dessert banana and is eaten in the immature stage. These provisions are usually cooked by boiling, but may also be crushed after being boiled. Another important source of carbohydrate is sadha roti; a wheat-based leavened bread, which is commonly eaten in Caribbean islands with a large South Asian population. The GI of these foods are not known and as such their inclusion in the menus for individuals with diabetes has been based mainly on reducing fat intakes and increasing intakes of complex carbohydrates (Caribbean Food and Nutrition Institute, 1994). An understanding of the physiological basis of carbohydrate exchange, as classified by the GI, may assist in optimising healthy food choices in the Caribbean and in emigrant populations. As such, knowledge of the GI of staples commonly used by Caribbean individuals could contribute to evidence-based meal planning and implementation of culturally sensitive risk-reduction dietary interventions.

In the present two-centre study the GI for boiled tubers, breadfruit, cooking banana, and sadha roti were determined in healthy volunteers. In another study the effect of crushing on the GI of selected tubers was also evaluated, since preparation methods and differing starch characteristics can both affect GI (Soh \& Brand-Miller, 1999).

\section{Methods}

\section{Study design}

Parallel studies were conducted at the Department of Preclinical Sciences, University of the West Indies, Trinidad and Tobago (site 1) and at the Department of Nutritional Sciences, University of Toronto, Canada (site 2) using a standard protocol as outlined by Wolever et al. (1991). The respective institutional ethics review committee approved the protocols and informed consent was obtained from all volunteers. The power of the tests with ten subjects was set at $80 \%$ to detect a $22 \%$ difference in areas under the glucose response curves (AUC) between the foods. This calculation assumed a variation of $22 \%$ within subjects (Wolever et al. 1991).

\section{Reference food}

White bread was prepared at both study sites using the recipe previously described (Wolever et al. 1994). In the absence of a bread maker at site 1 the ingredients were manually mixed and kneaded over a $3 \mathrm{~h}$ period, and baked in an electric oven at $190^{\circ} \mathrm{C}$ for $35 \mathrm{~min}$. At both study sites loaves were cooled at room temperature for $1 \mathrm{~h}$, weighed, cut into $50 \mathrm{~g}$ available carbohydrate portions (discarding the crust ends), placed in plastic bags and frozen. Before consumption the bread was warmed for $1 \mathrm{~min}$ in a microwave oven.

\section{Test foods and preparation}

These included breadfruit, cassava (Manihot esculenta), dasheen (Colocasia esculenta var. esculenta), eddoes (Colocasia esculenta var. antiquorum), cooking 'green' banana, tannia (Xanthosoma sagittifolium), Irish potato (Solanum tuberosum), and white yam (Dioscorea alata). Additionally, the leavened wheat-based bread, sadha roti, was tested. Foods eaten at site 1 were obtained on the day of harvest. With the exception of Irish potatoes, the foods eaten at site 2 were obtained from the local immigrant market and were usually about 1 week post-harvest. In all cases the inedible portions of the tubers were removed and discarded; for cassava and breadfruit this included both the peel and core. For the remaining tubers and cooking 'green' banana the peel was removed. The edible portions were washed and allowed to air dry at room temperature for $10 \mathrm{~min}$; they were then cut into chunks of approximately $25 \mathrm{~mm}$, and $50 \mathrm{~g}$ available carbohydrate portions (see Table 1) were boiled with minimal water and a pinch of salt. With the exception of breadfruit (18 and $8 \mathrm{~min}$ ) and green banana (15 and $8 \mathrm{~min}$ ) the tubers were cooked by gently boiling with the lid of the cooking vessel on for $20 \mathrm{~min}$, followed by simmering heat and the lid off for a further $10 \mathrm{~min}$. At site 1 the test foods (except sadha roti) were prepared in weekly batches, allowed to cool at room temperature (about $25^{\circ} \mathrm{C}$ ) for $10 \mathrm{~min}$ and stored in plastic bags at $-20^{\circ} \mathrm{C}$. These were thawed at room temperature and warmed for $1 \mathrm{~min}$ in a

Table 1. Composition of test foods (per $50 \mathrm{~g}$ available carbohydrate) ${ }^{\star}$

\begin{tabular}{|c|c|c|c|c|c|}
\hline Food & Weight (g) & Protein $(\mathrm{g})$ & Fat $(\mathrm{g})$ & Total carbohydrate $(\mathrm{g})$ & Fibre $(g)$ \\
\hline Dasheent & 131 & 0.4 & 0.3 & $52 \cdot 1$ & $2 \cdot 2$ \\
\hline Eddoest & 221 & 4.9 & 0.7 & 53.4 & 3.4 \\
\hline Irish potato† & 151 & 1.9 & 0.2 & 53.8 & 3.8 \\
\hline Tannia† & 135 & $2 \cdot 6$ & 0.3 & $52 \cdot 0$ & $2 \cdot 0$ \\
\hline White yam $\dagger$ & 300 & $5 \cdot 8$ & 0.2 & $52 \cdot 1$ & $2 \cdot 1$ \\
\hline White flour & 67 & 6.9 & 0.7 & $51 \cdot 8$ & 1.8 \\
\hline Cassavał & 159 & 4.9 & 0.6 & $54 \cdot 0$ & 4.0 \\
\hline Green bananał & 223 & $2 \cdot 7$ & $1 \cdot 0$ & 54.9 & 4.9 \\
\hline Breadfruit $\ddagger$ & 216 & $2 \cdot 4$ & 0.4 & 53.2 & 3.2 \\
\hline
\end{tabular}


microwave oven before consumption. At site 2 the test tubers were prepared on the day before each test, allowed to cool $\left(22^{\circ} \mathrm{C}\right)$ for $10 \mathrm{~min}$ and refrigerated; they were heated in a microwave oven for $1 \mathrm{~min}$ before being served. At site 1 sadha roti was prepared on the test day from $67.3 \mathrm{~g}$ portions of white flour (Five Roses; ADM Agri-Industries Ltd, Decatur, IL, USA). The flour was dry mixed with $1 \mathrm{~g}$ salt and $1 \mathrm{~g}$ baking powder. Following the addition of approximately $50 \mathrm{ml}$ water the mixture was kneaded to produce a soft dough. A ball of dough was then flattened with a rolling pin to approximately $150 \mathrm{~mm}$ in circumference and $12.5 \mathrm{~mm}$ thick. It was then evenly cooked on a hot plate at moderate heat for $5 \mathrm{~min}$, turning occasionally until done.

\section{Study 1}

At site 1, eight normal volunteers (age 25.4 (SEM 1.5) years; four male, four female; BMI 21.5 (SEM 0.8$) \mathrm{kg} / \mathrm{m}^{2}$ ) ate cassava, breadfruit, cooking 'green' banana and sadha roti. The portion sizes were based on published values for total carbohydrate and dietary fibre (Caribbean Food and Nutrition Institute, 1998) and available carbohydrate was calculated by difference (Table 1 ).

\section{Study 2}

At site 2, ten normal volunteers (age 29 (SEM 4) years; four male, six female; BMI $\left.21.9(\mathrm{SEM} 0.8) \mathrm{kg} / \mathrm{m}^{2}\right)$ ate dasheen, eddoes, white yam, tannia and Irish potato. The portion sizes were based on proximate (ash, acid hydrolysis for fat, $100^{\circ} \mathrm{C}$ oven for moisture, Dumas method $(\mathrm{N} \times 5.70)$ for protein, total carbohydrate by difference) and total dietary fibre analysis (gravimetric method) using standard AOAC methods (Association of Official Analytical Chemists, 1995) with available carbohydrate being defined as total carbohydrate minus total dietary fibre (Table 1).

\section{Study 3}

At site 2 the tubers from study 2 with the highest and lowest GI values were chosen. Irish potato was used as a comparison or reference food in order to validate the procedure used to study the effects of crushing on the selected tubers. Six of the volunteers from study 2 participated in study 3. Available carbohydrate portions $(50 \mathrm{~g})$ of the foods were boiled and either left uncrushed or crushed before storage in the refrigerator, as in study 2 .

\section{Experimental procedure}

Following $12 \mathrm{~h}$ overnight fasts volunteers ate $50 \mathrm{~g}$ available carbohydrate portions of the foods weekly. They each started and ended with white bread; the second white bread and the test foods were randomly eaten. At site 1 all foods were taken with $250 \mathrm{ml}$ water, at site 2 the volunteers chose water or unsweetened tea or coffee, but the chosen beverage was constant for all studies. Fingerpick capillary blood samples were taken before starting the meals. Volunteers were then asked to consume the foods within $10 \mathrm{~min}$ and to remain seated for the duration of the test. Further blood samples were taken at 15, 30, 45, 60, 90, and $120 \mathrm{~min}$. Blood samples were taken into fluoro-oxalate tubes and either stored at $-20^{\circ} \mathrm{C}$ (site 2) or quickly centrifuged to obtain plasma which was stored at $-20^{\circ} \mathrm{C}$ (site 1 ). At site 1 capillary plasma glucose was measured using a commercial hexokinase end-point method with blank correction (Sigma Chemical Co., St Louis, MO, USA). Capillary whole-blood glucose was measured at site 2 using an automatic analyser (2300 Stat Glucose Analyser; YSI Inc., Yellow Springs, OH, USA). All glucose assays were performed within $48 \mathrm{~h}$ of sampling. At both sites the inter-assay and intra-assay $\mathrm{CV}$ for the glucose assay were approximately $3 \%$.

\section{Statistical analysis}

Incremental AUC ignoring area beneath the fasting level were calculated geometrically (Wolever et al. 1991). The AUC for each food was expressed as a percentage of the mean area for the three white-bread tests and the resulting values averaged to give the food GI based on white bread. Because it is now the preferred practice to report GI values using glucose, this was derived by multiplying the whitebread-based GI by 0.71 (since the GI of white bread is 71 when glucose has the reference GI of 100; Wolever et al. 2003). The test-food GI for each subject was averaged to give the mean GI for each test food. The AUC for pooled repeated white-bread tests were compared using one-way ANOVA. The AUC and GI values were not normally distributed and so statistical analysis was performed by using Friedman's ANOVA by ranks with Dunnett's post hoc test. The blood glucose concentrations at each time point were compared using conventional twoway ANOVA, followed by Tukey's test to protect for multiple comparisons. Differences were considered statistically significant at $P<0 \cdot 05$.

\section{Results}

The blood glucose response curves of the test foods and white bread for studies 1 and 2 are shown in Fig. 1. The mean, standard deviation and $\mathrm{CV}$ of the AUC values for repeated white-bread tests are given in Table 2 for each volunteer and each site. There was no significant difference between the mean AUC $(P=0.5)$ or the mean $\mathrm{CV}$ $(P=0.09)$ between the different centres. However, differences between subjects at each site were highly significant $(P<0 \cdot 001)$.

Table 3 shows the AUC, the white-bread-based GI values, as well as the glucose-based GI results for the test foods. Two-way ANOVA showed there was no significant effect of subject on GI in any of the three studies. In study 1 cassava was found to have a significantly higher $\left(\chi^{2} 11.9\right.$, degrees of freedom $\left.4 ; P=0.018\right)$ ranked GI than the other foods tested at site 1 . In study 2 the differences in AUC and GI among the foods tested were not statistically significant.

The blood glucose response curves for the three boiled (whole and crushed) tubers compared with the response for white bread are shown in Fig. 1. Table 4 shows the AUC and GI values for the boiled + uncrushed and 


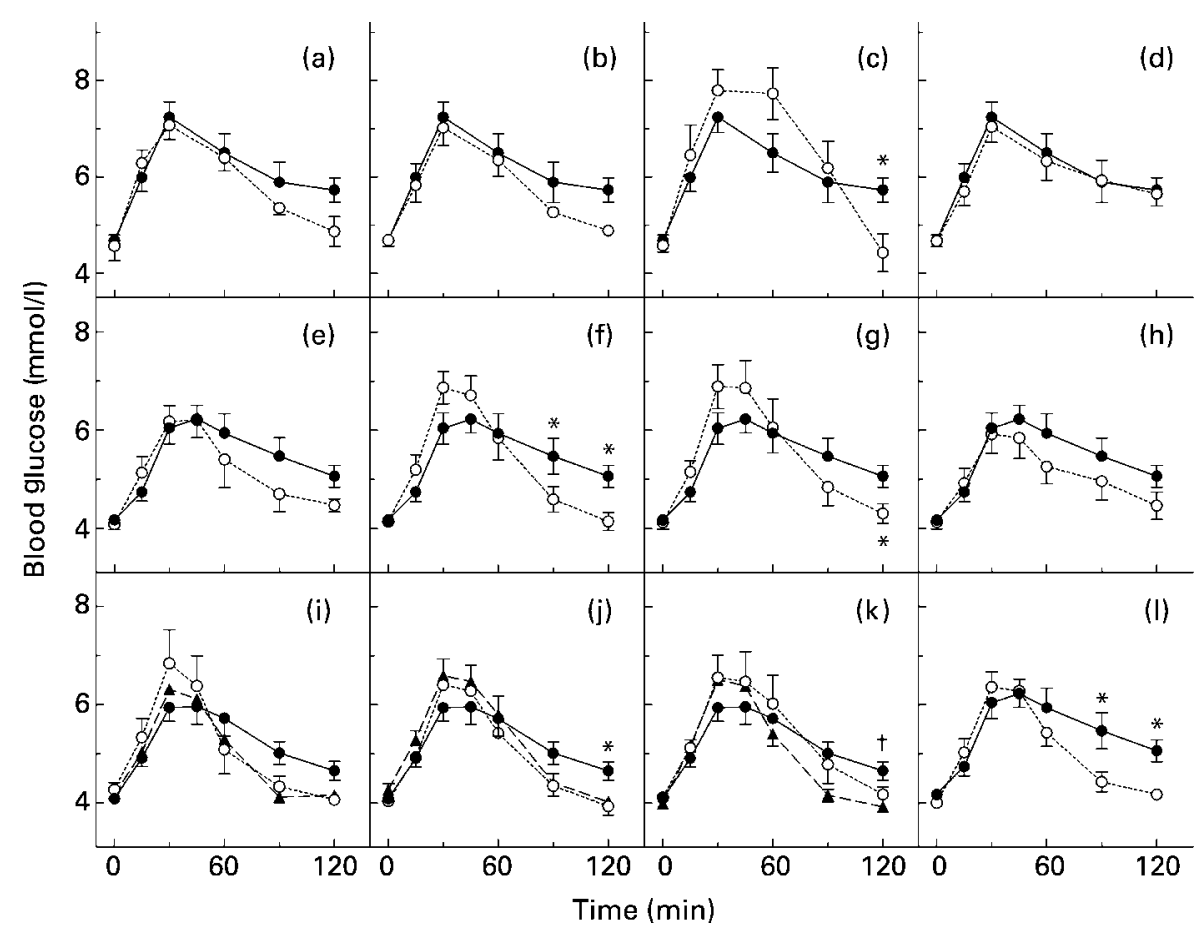

Fig. 1. Blood glucose responses in groups of eight to ten normal subjects elicited by test foods (green banana (a), breadfruit (b), cassava (c), roti (d), tannia (e), Irish potato (f), dasheen (g), eddoe (h), crushed tannia (i), crushed Irish potato (j), crushed dasheen $(k)$, yam (l)) $(O$, $\mathbf{\Delta})$ compared with white bread $(\bullet)$ consumed by the same subjects. For (i) to $(\mathrm{k})$, the results for uncrushed tubers are shown $(\mathrm{O})$ as well as those for crushed tubers $(\boldsymbol{\Lambda})$. Mean values are shown, with standard errors of the mean represented by vertical bars. Bars have not been shown if they are smaller than the symbol or overlap other symbols or bars. Mean values were significantly different from that for white bread $(P<0.05)$ : * uncrushed foods; $\dagger$ crushed foods.

boiled + crushed tubers compared with the response for white bread. The AUC and the GI values of uncrushed and crushed preparations of the foods tested were not significantly different. When data for boiled whole dasheen,

Table 2. Incremental areas under the glucose response curve $(\mathrm{mmol} \times \mathrm{min} / \mathrm{l})$ for white bread

\begin{tabular}{|c|c|c|c|c|c|c|}
\hline \multirow[b]{2}{*}{ Code } & \multicolumn{3}{|c|}{ Volunteer } & \multirow[b]{2}{*}{ Mean } & \multirow[b]{2}{*}{ SD } & \multirow[b]{2}{*}{ CV (\%) } \\
\hline & no. 1 & no. 2 & no. 3 & & & \\
\hline \multicolumn{7}{|l|}{ Site 1} \\
\hline 101 & 203 & 179 & 218 & 200 & 20 & 10 \\
\hline 102 & 167 & 156 & 223 & 182 & 36 & 20 \\
\hline 103 & 117 & 105 & 102 & 108 & 8 & 7 \\
\hline 104 & 103 & 120 & 96 & 106 & 12 & 11 \\
\hline 105 & 252 & 251 & 231 & 245 & 12 & 5 \\
\hline 106 & 221 & 266 & 199 & 228 & 34 & 15 \\
\hline 107 & 158 & 171 & 187 & 172 & 15 & 9 \\
\hline 108 & 238 & 288 & 197 & 241 & 46 & 19 \\
\hline Mean & 182 & 192 & 182 & 185 & 23 & 12 \\
\hline SEM & 20 & 24 & 19 & 19 & 5 & 2 \\
\hline \multicolumn{7}{|l|}{ Site 2} \\
\hline 201 & 146 & 148 & 123 & 139 & 14 & 10 \\
\hline 202 & 462 & 393 & 452 & 435 & 37 & 9 \\
\hline 203 & 85 & 97 & 179 & 120 & 51 & 43 \\
\hline 204 & 71 & 80 & 86 & 79 & 7 & 10 \\
\hline 205 & 212 & 135 & 134 & 160 & 45 & 28 \\
\hline 206 & 121 & 125 & 205 & 150 & 47 & 32 \\
\hline 207 & 167 & 127 & 147 & 147 & 20 & 14 \\
\hline 208 & 75 & 114 & 120 & 103 & 24 & 24 \\
\hline 209 & 116 & 131 & 96 & 114 & 18 & 15 \\
\hline 210 & 158 & 190 & 142 & 163 & 24 & 15 \\
\hline Mean & 161 & 154 & 168 & 161 & 29 & 20 \\
\hline SEM & 36 & 28 & 33 & 32 & 5 & 4 \\
\hline
\end{tabular}

Irish potato and tannia from both studies (study 2 and 3) were pooled, their GI values, respectively, were 76 (SEM 7), 69 (SEM 6) and 55 (SEM 5), with the difference between dasheen and tannia being statistically significant $(P=0 \cdot 015)$.

\section{Discussion}

The GI values of staples commonly eaten in the Caribbean were determined in the present two-centre study using a standard protocol. The foods selected for testing were based on $24 \mathrm{~h}$ recalls (Wolever et al. 2002), food balance sheets (Sinha, 1995) and discussions with nutrition practitioners in the Caribbean. There was good concordance between the two centres with respect to the mean and within-subject variation of glycaemic responses elicited by white bread. Although there was significant variation in the glucose response to white bread between subjects, there was no significant variation in GI values between subjects. Additionally, in a recent study white bread made from flour obtained at the respective study sites was shown to have comparable GI (Wolever et al. 2003). Based on the mean GI values obtained for dasheen (77 and 75), tannia (60 and 50) and Irish potato (71 and 66) in studies 2 and 3, the average between-study standard deviation was 6.6, which is less than the average between-laboratory standard deviation of 9 previously reported (Wolever et al. 2003). We did not undertake measurements of insulin in the present study due to financial constraints but also because our main objective was to generate GI data for Caribbean foods. 
The method used to measure glucose and the type of blood samples analysed differed at the two study sites. However, results from a multi-centre study, which included both study sites, showed that derivation of GI is not affected by the analytical method used for glucose determination (Wolever et al. 2003). Additionally, GI values obtained from capillary whole blood or plasma were not different and produced a smaller standard deviation in comparison with venous blood (Wolever et al. 2003). At site 2, volunteers were allowed the choice of water, unsweetened tea or coffee, whereas at site 1 all meals were eaten with water. The former practice does not affect the glucose AUC significantly (Young \& Wolever, 1998), and is considered acceptable providing that volunteers keep constant their chosen drink for the duration of the GI studies (Wolever et al. 1991).

We were unable to detect significant differences in glycaemic response between the tubers in the individual studies, despite apparently large-enough differences in mean AUC: $26 \%$ in study 2, dasheen $v$. eddoe; $34 \%$ in study 3 , uncrushed dasheen $v$. crushed tannia. The original power analysis indicates that the probabilities of failing to detect differences of 26 and $34 \%$, respectively, are 0.16 and 0.04 . Thus, in study 2 the largest difference between tubers, $26 \%$, was such that there was a relatively high chance $(0 \cdot 16$, or about $1: 6)$ of failing to detect it. On the other hand, in study 3 it is improbable $(P<0.05)$ that the failure to detect the $34 \%$ difference in AUC was due to chance, and hence is more probably due to the existence of greater variability than expected. However, when the results for the whole tubers in studies 2 and 3 were pooled, the difference in GI between dasheen and tannia became significant. Even if a very conservative Bonferroni correction is applied to the pooled data to adjust for the fact that the same data were used for two statistical tests, the difference is still significant $(P=0 \cdot 03)$.

The tubers reported in the present paper have not been studied previously, so it was important to calibrate our studies with a food, preferably a tuber, with a known GI. Irish potato was chosen for this purpose. The GI values obtained for Irish potato in studies 2 and 3 (71 and 66) not only agree with each other but also are similar to GI values we have previously published for boiled or baked Prince Edward Island, white and new potatoes (range 55-70) (Jenkins et al. 1981, 1983; Wolever et al. 1994).

The studies showed that the nine different test foods have GI values which varied over a $1 \cdot 5$-fold range. The reason for the relative differences is not known; however, one possibility is that the physical and chemical characteristics of the starch in these foods vary. Further work is therefore needed to determine the characteristics of the starch in the various tubers. The cook-cooling-re-warming cycle to which the tubers were subjected could have affected the amount of resistant starch (RS) they contained. About $7 \%$ of the starch in reheated boiled potatoes escapes digestion in the small intestine starch compared with about $3 \%$ in freshly cooked potato (Englyst \& Cummings, 1987), a difference which seems too small to have a detectable effect on glycaemic responses. The RS content of foods similar to those reported here (roti, yam, eddoes, cassava, 
Table 4. Effect of crushing tubers on incremental area under the glucose curve (AUC; $\mathrm{mmol} \times \mathrm{min} / \mathrm{l})$ and glycaemic index (GI)

\begin{tabular}{|c|c|c|c|c|c|c|c|c|c|c|c|c|c|c|}
\hline & \multicolumn{2}{|c|}{$\begin{array}{l}\text { Uncrushed } \\
\text { dasheen }\end{array}$} & \multicolumn{2}{|c|}{$\begin{array}{l}\text { Uncrushed } \\
\text { Irish potato }\end{array}$} & \multicolumn{2}{|c|}{$\begin{array}{l}\text { Uncrushed } \\
\text { tannia }\end{array}$} & \multicolumn{2}{|c|}{$\begin{array}{l}\text { Crushed } \\
\text { dasheen }\end{array}$} & \multicolumn{2}{|c|}{$\begin{array}{l}\text { Crushed Irish } \\
\text { potato }\end{array}$} & \multicolumn{2}{|c|}{$\begin{array}{c}\text { Crushed } \\
\text { tannia }\end{array}$} & \multicolumn{2}{|c|}{ White bread } \\
\hline & Mean & SEM & Mean & SEM & Mean & SEM & Mean & SEM & Mean & SEM & Mean & SEM & Mean & SEM \\
\hline AUC & 155 & 40 & 130 & 23 & 112 & 29 & 129 & 15 & 127 & 13 & 103 & 13 & 145 & 22 \\
\hline $\mathrm{GI}_{\mathrm{wb}}$ & 105 & 17 & 93 & 14 & 71 & 11 & 93 & 8 & 94 & 9 & 74 & 7 & $100^{\star}$ & - \\
\hline GI & 75 & 12 & 66 & 10 & 50 & 8 & 66 & 6 & 66 & 7 & 52 & 5 & $71^{*}$ & - \\
\hline
\end{tabular}

$\mathrm{GI}_{\mathrm{wb}}$, $\mathrm{Gl}$ based on bread reference (i.e. Gl of white bread $=100$ ).

${ }^{*}$ No SEM shown because of zero degrees of freedom for a defined value.

potato) is low, with a range of $1.8-3.4 \mathrm{~g} / 11 \mathrm{~g}$ dry weight (Platel \& Shurpalekar, 1994). More recently, the effect of RS on GI was examined using barley (about $15 \%$ RS), and there was no significant effect on GI after adjusting for RS content (Wolever et al. 2003).

The finding that crushing did not result in significant differences in GI suggests that this procedure did not affect the foods' physical structure sufficiently to produce elevated glycaemic responses. The GI for Irish potato did not increase when it was crushed in these studies. This is consistent with the findings of a previous study in which the GI of boiled Prince Edward Island potatoes (64) did not increase significantly when the potatoes were mashed (74) (Wolever et al. 1994).

Using published criteria (Brand-Miller et al. 2003b) it is possible to classify dasheen and cassava as being high-GI foods, whereas the other tubers studied (i.e. yam, tannia, eddoes, and Irish potato, cooking 'green' banana, and breadfruit) and roti can be designated intermediate-GI foods. Food consumption patterns are not available for most Caribbean countries; however, of the staple foods tested, cassava, dasheen, Irish potato, yam and roti are probably eaten more often than 'green' banana, breadfruit, eddoes and tannia. When the former are added to the other frequently used staples (bread and rice) it becomes apparent that the Caribbean diet is probably one with a high GI. This is supported by the finding of a mean diet GI of 58 in a sample of healthy individuals in Trinidad and Tobago (Wolever et al. 2002), which can be compared with median values of 52 and 50, respectively for middle-aged men and women in the USA (Salmeron et al. 1997a,b).

The range of GI between staples is sufficiently large, and could result in beneficial health effects if those consuming a Caribbean diet reduced their intakes of staples with high GI and increased the consumption of those with intermediate GI. This is particularly important since small changes in diet GI are associated with a significant reduction in CHD risk (Liu et al. 2000), diabetes risk (Salmeron et al. $1997 a, b)$ and improvements in insulin sensitivity and glycaemic control (Frost et al. 1998; Wolever \& Mehling, 2002; Brand-Miller et al. 2003a). Ideally, low-GI Caribbean staples need to be identified and their usage promoted; however, this will require further studies. The findings of the present study can provide useful guidance for health workers involved in meal planning for diabetics and diabetes education programmes, especially in Caribbean countries and in Caribbean migrants. It can also be used to achieve healthy eating and plan chronic-disease risk-reduction programmes in high-risk populations.
It should now be possible to advocate for evidence-based changes in the type and frequency of staples used by Caribbean individuals.

\section{Acknowledgements}

The present work was partially supported by grants from the Caribbean Health Research Council and the University of the West Indies (St Augustine) Research and Publication Funds. We thank Mr B. Mahabir, Ms N. Ramdhanie, Ms A. Williams, Mr C. Bridgemohan, the National Herbarium of Trinidad and Tobago, and the volunteers for their valuable contributions.

\section{References}

Association of Official Analytical Chemists (1995) Official Methods of Analysis, 16th ed. Arlington, VA: AOAC.

Brand JC, Colagiuri S, Crossman S, Allan A, Roberts DCK \& Truswell AS (1992) Low-glycemic index foods improve long-term glycemic control in NIDDM. Diabetes Care 15, $562-566$.

Brand-Miller J, Hayne S, Petocz P \& Colagiuri S (2003a) Lowglycemic index diets in the management of diabetes: a metaanalysis of randomized controlled trials. Diabetes Care 26, 2261-2267.

Brand-Miller J, Wolever TMS, Foster-Powell K \& Colagiuri S (2003b) The New Glucose Revolution: the Authoritative Guide to the Glycemic Index. New York: Marlowe \& Company.

Byrnes SE, Brand-Miller JC \& Denyer GS (1995) Amylopectin starch promotes the development of insulin resistance in rats. J Nutr 125, 1430-1437.

Caribbean Food and Nutrition Institute (1994) Meal Planning for Diabetes, 4th ed., Kingston, Jamaica: Caribbean Food and Nutrition Institute Press.

Caribbean Food and Nutrition Institute (1998) Food Composition Tables for Use in the English-Speaking Caribbean, 2nd ed., Kingston, Jamaica: Caribbean Food and Nutrition Institute Press.

Cooper RS, Rotimi CN, Kaufman JS, Owoaje EE, Fraser H, Forrester T, Wilks R, Riste LK \& Cruickshank JK (1997) Prevalence of NIDDM among populations of the African Diaspora. Diabetes Care 20, 343-348.

Cruickshank JK, Cooper J, Burnett M, MacDuff J \& Drubra U (1991) Ethnic differences in fasting plasma C-peptide and insulin in relation to glucose tolerance and blood pressure. Lancet 338, 842-847.

Englyst NH \& Cummings JH (1987) Digestion of polysaccharides of potato in the small intestine of man. Am J Clin Nutr 45, $423-431$. 
Food and Agriculture Organization of the United Nations (1998) Carbohydrates in Human Nutrition. FAO Food and Nutrition Paper no. 66. Rome: FAO.

Ford ES \& Liu S (2001) Glycemic index and serum high-density lipoprotein cholesterol concentration among US adults. Arch Intern Med 161, 572-576.

Frost G, Leeds A, Trew G, Margara R \& Dornhorst A (1998) Insulin sensitivity in women at risk of coronary heart disease and the effect of a low glycemic index diet. Metabolism 47, $1245-1251$

Gulliford MC (1996) Epidemiological transition in Trinidad and Tobago, West Indies 1953-1992. Int J Epidemiol 25, 357-365.

Gulliford MC, Ariyanayagam-Baksh SM, Bickram L, Picou D \& Mahabir D (1995) Counting the cost of diabetic hospital admissions from a multi-ethnic population in Trinidad. Diabet Med 12, 1077-1085.

Jenkins DJA, Wolever TMS, Jenkins AL, Thorne MJ, Lee R, Kalmusky J, Reichert R \& Wong GS (1983) The glycaemic index of foods tested in diabetic patients: a new basis for carbohydrate exchange favouring the use of legumes. Diabetologia 24, 257-264.

Jenkins DJA, Wolever TMS, Kalmusky J, et al. (1987) Low-glycemic index in hyperlipidemia: use of traditional starchy foods. Am J Clin Nutr 46, 66-71.

Jenkins DJA, Wolever TMS, Taylor RH, Barker HM, Fielden H, Baldwin JM, Bowling AC, Newman HC, Jenkins AL \& Goff DV (1981) Glycemic index of foods: a physiological basis for carbohydrate exchange. Am J Clin Nutr 34, 362-366.

Liu S \& Manson JE (2001) Dietary carbohydrates, physical activity, obesity, and the 'metabolic syndrome' as predictors of coronary heart disease. Curr Opin Lipidol 12, 395-404.

Liu S, Willett W, Stampfer M, Hu F, Franz M, Sampson L, Hennekens C \& Manson J (2000) A prospective study of dietary glycemic load, carbohydrate intake and risk of coronary heart disease in US women. Am J Clin Nutr 71, 1455-1461.

Platel K \& Shurpalekar KS (1994) Resistant starch content of Indian foods. Plant Foods Hum Nutr 45, 91-95.
Salmeron J, Ascherio A, Rimm EB, Colditz GA, Spiegelman D, Jenkins DJ, Stampfer MJ, Wing AL \& Willett WC (1997a) Dietary fiber, glycemic load, and risk of NIDDM in men. Diabetes Care 20, 545-550.

Salmeron J, Manson JE, Stampfer MJ, Colditz GA, Wing AL \& Willett WC (1997b) Dietary fiber, glycemic load, and risk of non-insulin-dependent diabetes mellitus in women. JAMA 227, 472-477.

Sinha DP (1995) Changing patterns of food, nutrition and health in the Caribbean. Nutr Res 15, 899-938.

Soh NL \& Brand-Miller J (1999) The glycaemic index of potatoes: the effect of variety, cooking method and maturity. Eur $J$ Clin Nutr 53, 249-254.

Thomas DE, Brotherhood JR \& Brand JC (1991) Carbohydrate feeding before exercise: effect of glycemic index. Int $J$ Sports Med 12, 180-186.

Wolever TMS, Isaacs RLC \& Ramdath DD (2002) Lower diet glycaemic index in African than South Asian men in Trinidad and Tobago. Int J Food Sci Nutr 53, 297-303.

Wolever TMS, Jenkins DJA, Jenkins AL \& Josse RG (1991) The glycemic index: methodology and clinical implications. Am J Clin Nutr 54, 846-854.

Wolever TMS, Katzman-Relle L, Jenkins AL, Vuksan V, Josse RG \& Jenkins DJA (1994) Glycaemic index of $102 \mathrm{com}-$ plex carbohydrate foods in patients with diabetes. Nutr Res 14, 651-669.

Wolever TMS \& Mehling C (2002) High-carbohydrate-low-glycaemic index dietary advice improves glucose disposition index in subjects with impaired glucose tolerance. $\mathrm{Br} J$ Nutr 87, 477-487.

Wolever TMS, Vorster HH, Björck I, et al. (2003) Determination of the glycaemic index of foods: interlaboratory study. Eur $J$ Clin Nutr 57, 475-482.

Young KWH \& Wolever TMS (1998) Effect of volume and type of beverage consumed with a standard test meal on postprandial blood glucose responses. Nutr Res 18, $1857-1863$. 